\title{
2006-1460: USING EDUCATIONAL "TOYS" TO RECRUIT FEMALE STUDENTS INTO AN ELECTRICAL ENGINEERING TECHNOLOGY PROGRAM
}

\section{Jeffrey Richardson, Purdue University}

Jeffrey J. Richardson is an Assistant Professor for the Electrical and Computer Engineering Technology Department at Purdue University where he teaches introductory and advanced embedded microcontroller courses. At Purdue, he is active in Project Lead the Way, recruitment and retention of students, applied research and has written several conference papers related to teaching embedded microcontroller systems.

\section{Emily Toner, Purdue University}

EMILY C. TONER is a graduate student pursuing her Master's Degree in the Electrical and Computer Engineering Technology Department at Purdue University. Her teaching experience includes assisting in introductory programming and circuit analysis courses. Her industrial experience includes controls engineering, manufacturing operations, and project management. 


\title{
Using Educational "Toys" to Recruit Female Students into an Electrical Engineering Technology Program
}

\begin{abstract}
Recruiting is a major strategic area for many engineering and technology programs across the country. The recruitment of minorities and especially females is of high importance in these programs. As part of the recruiting initiative, a group of female Project Lead the Way students from area high schools attend a one-day workshop hosted by the College of Technology at Purdue University. The students attend various workshops hosted by the different departments within the college. The goal is to introduce the students to the various technology fields and the associated career within these fields. Once provided with this information, the hope is that the students will consider attending the College of Technology at Purdue University.

The Electrical and Computer Engineering Technology Department at Purdue University has employed the use of children's educational toys and learning devices. An educational toy is created by the students when attending the Electrical Engineering Technology workshop. The project is based on a Leap Frog learning activity (Fridge Phonics ${ }^{\mathrm{TM}}$ ) which teaches children the letter names, letter sounds and learning sounds for the alphabet. The students are provided with a complete development environment for an embedded microcontroller which includes a digital speech device. The students complete the design of a toy that reads a decimal number between 0 and 9 . When operated, the toy speaks the name of the number, and then spells the name for the user and repeats the name of the number. The students were successful at understanding the technical concepts required to complete the project and rated the workshop as excellent.
\end{abstract}

\section{Introduction:}

The College of Technology based its Project Lead the Way workshop by incorporating three related ideas: helping female students to build their confidence in technology, providing a hands-on opportunity to explore engineering, and highlighting technical careers. The students who attended the workshop would gain insight on technical fields that they may not have previously considered.

Several articles have been written regarding females' interest in technical careers ${ }^{1,2,3,4}$. The level of interest a student may have for engineering can be understood by studying the differences in male and female learning styles. These differences typically become evident at a young age. As children, girls and boys typically play with different types of games; girls play in a way that accentuates relationships while boys are involved with games that emphasize building ${ }^{1}$. As these youngsters enter classes that are specific to 
science, technology, engineering, and math (STEM), girls generally have less experience in the hands-on application of learning principles than boys. For STEM subjects, girls may have less expertise with computers, affecting their confidence, while boys have a better understanding of computers, giving them an advantage. According to Donna Milgram, National Institute for Women in Trades, Technology \& Science, "for females, confidence is a predictor of success in the STEM classroom." Three ways in which instructors can build confidence in female students is by creating a supportive environment, involving female role models, and positive reinforcement ${ }^{1}$.

The workshop students were placed in groups with other females where they began by discussing children's toys or learning tools. For the participants, the topic was something that high school age students could relate to and discuss. Current female students in ECET were involved in the conversation and talked about children's learning toys and advancements in product electronics. As the students completed each section of their workshop project, they were motivated to use the additional time to investigate the hardware and software and incorporate their own ideas.

Females tend to be more interested in how technology will be used rather than discussing how big an engine is or how fast a processor runs ${ }^{1}$. A Carnegie-Mellon Study cites that female students were observed to be "much more positive about getting through a tedious coding class when they understood the purpose of it." If the value of the technology's application or context proves to be attractive or worthwhile, female students will be more motivated $^{1}$. Teachers should address the application of technology early on in the class to ensure the interests of all students are captured.

The workshop project was developed in a manner that allowed students to create a children's learning toy, similar to the recently launched Leap Frog FridgePhonics ${ }^{\mathrm{TM}}$ product. Initial topics presented in the workshop identified how electronics, inside children's toys, were able to incorporate a variety of interactions with children. The discussion involved moving parts with small motors, lighting buttons with inputs and outputs, and creating sounds with speakers. The application for the workshop technology was perceived as an innovative way to help kids learn numbers and spelling.

\section{Theory of Operation:}

The Leapfrog Fridge Phonics ${ }^{\mathrm{TM}}$ has two main components: the base and the letters. The individual letters have a series of ridges along the bottom edge of each digit. These ridges serve as a mechanism to uniquely identify each of the letters.

The letter's ID is read by a series of switches located in the base of the unit. As each digit is placed into and removed from the unit, a new binary pattern is created. Once a letter has been inserted, the user must

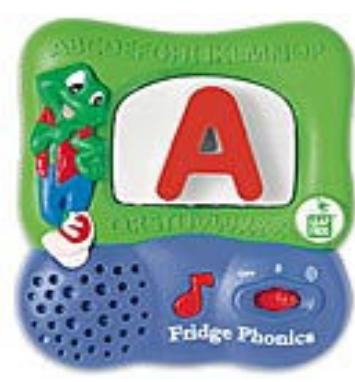

Figure 1 - Leapfrog Fridge Phonics Photo from: www.leapfrog.com 
The project created during the workshop operates on the same basic principles. A series of switches are set to identify the number. A push button is then used to start the learning sequence. In our version, the unit first speaks the number, then spells the number by annunciating each individual letter and finally speaks the number again.

\section{Development Environment:}

The development environment utilized in this project was constructed from standard microcontroller development peripherals. The project is based around an Atmel Atmega 162 8-bit embedded microcontroller development board. The board is a generalpurpose microcontroller with four 8-bit Input / Output (I/O) ports and one 3-bit I/O port. A basic block diagram is shown below in figure 2 .

The microcontroller is connected to a set of 8 toggle switches and 1 push button that provide standard TTL level signals. The toggle switches and push button are located on a separate lights and switches I/O peripheral board. This board provides the basic functionality found in most digital trainer boards. The toggle switches are used to determine the number that is to be spoken. The push button is used to signal when the number is to be spoken.

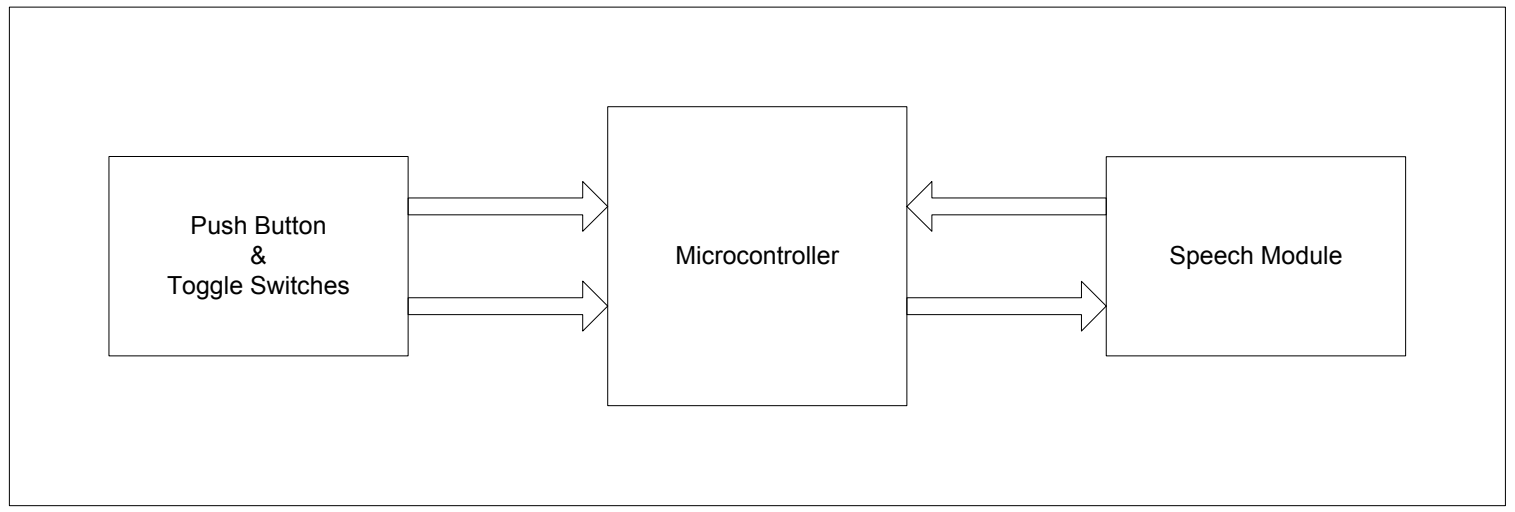

Figure 2 - Block Diagram of Development Environment

A speech module is utilized to provide the audio for this project. This version of the project utilized the DigiTalker Voice modules manufactured by National Semiconductor. The module has a vocabulary that includes numbers, letters, and a limited number of words. The microcontroller provides 8-bits of data to represent the word, number or letter to be spoken. The microcontroller also provides an output control line to signal the voice module to speak. A control line is connected from the voice module to the microcontroller to synchronize the microcontroller and the voice module while the voice module is speaking the current word. Although older technology, these modules perform extremely well in this application. 


\section{Actual Workshop:}

The actual workshop starts with a display and demonstration of various toys that employ some type of electronics. These include toys that design purely for entertainment as well as devices design to help children with educational activities. This part of the workshop serves multiple purposes. It serves as a mechanism to get the participants interested in the upcoming activities and gets the students to start thinking about various other devices that utilize electronics to help people. The demonstration of these devices also serves as a transition into the next part of the workshop.

Once the demonstration of the electrical toys has been completed, the workshop moves the focus of the participants to the chalkboard. The chalkboard has been divided into two sections prior to the workshop starting. One section is covered by an overhead projector screen and will be discussed shortly. The other side of the chalkboard contains alphabet refrigerator magnets. These magnets are simply attached to the board in a somewhat random pattern. The facilitator of the workshop then briefly discusses how one might utilize these normal magnets in an educational environment while making connections to the education toys that were demonstrated earlier. Joking comparisons are made between the magnets and "sticks and rocks" when compared to the modern electronic toys.

The workshop facilitator then poses a question to the workshop participants... "How could electronics be utilized to help children learn the alphabet or the number system?" After a few brief moments, the facilitator raises the overhead project screen to reveal the Leapfrog Fridge Phonics ${ }^{\text {TM }}$. The next few minutes of the workshop are used to discuss the theory of operation of the fridge phonics education device and to demonstrate the product. This demonstration reveals the details of how the letters are encoded and how the base module is able to determine which letter (if any) is present.

The next portion of the workshop involves the basic design of a learning device to teach a user the name of numbers and how to spell them. The facilitator leads the participants to the development system described earlier. In preparation for the workshop, each participant has been provided with a laboratory station fully equipped to develop a toy.

Since the identity of the numbers will be encoded in a binary fashion, the binary numbering system is briefly taught to the workshop participants. Once the binary numbering system has been demonstrated, binary patterns are assigned to the individual numbers. These binary patterns will be set on the toggle switches to identify the number of interest.

The binary numbers are read by the microcontroller through a program developed with the $\mathrm{C}$ programming language. The participants are provided with a base program that contains a significant portion of the code required for the exercise. The workshop facilitator then leads the participants through the process of adding the remaining code necessary to implement one of the numbers. During this process, the facilitator teaches basics about the programming language and steps involved in creating a microcontrollerbased project as well the details for generating speech from the voice module. 
Armed with this new information, the workshop participants are instructed to add one or more of the remaining numbers to their device. For this portion of the workshop, the facilitator and the current ECET female students work individually with the participants and answer any questions that may arise.

The workshop ends with an opportunity for the participants to interact with the workshop facilitator and current female ECET students. In addition, to the staff, the educational and electrical devices used during the workshop are available for inspection and operation.

\section{Assessment:}

The students that participated in this project rated the workshop as excellent. They really enjoyed learning about the role that electronics plays in the educational and childhood development activities. The participants also enjoyed learning about the specifics of how to create a learning activity.

The students were able to follow the concepts that were taught during the process. The students were able to understand the binary number system and apply it to the problem at hand. The students were also able to follow the $\mathrm{C}$ language program and make the required modifications to add the desired functionality.

The true test of this project is still to be answered. The ultimate test is in the number of students involved in the project that enroll and ultimately graduate from the Electrical and Computer Engineering Technology Department. These figures will not be available for several years. Efforts are being made to track the students who participated in this workshop to measure their potential future enrollment.

\section{Conclusions:}

This project involves a small subset of the skills required for an electrical engineering type occupation. It allows the workshop participants a view into the steps required to plan, construct, program and test a product. The project also demonstrates how electronics can be employed to teach and enhance education. The workshop plants a seed with the participants to start them thinking about other uses of technology and electronics.

Another important outcome of this project was to educate the students on what Electrical and Computer engineering technology is and is not. The ECET curriculum is compared to similar programs at Purdue University such as Electrical and Computer Engineering, Mechanical Engineering Technology, and Mechanical Engineering. For Purdue's College of Technology, there is a distinction between its programs and those programs within the College of Engineering. College of Technology students should expect similar rigor in their studies, however, its programs typically focus on applied science rather than theoretical design throughout engineering and research. 


\section{References:}

[1] Milgram, D., "Gender Differences in Learning Style Specific to Science, Technology, Engineering and Math (STEM)," National Institute for Women in Trades, Technology and Science, N.D.

[2] Kam, M., "Why Janie won't do to Engineering School," IEEE - The Interface, November 2005.

[3] Wasburn, M.H., Miller, S.G., "Can a Women in Technology Freshman Seminar Change Student Attitudes," ASEE Annual Conference, 2005.

[4] DeBartolo, E., Bailey, M., "A Continuous Series of Outreach Programs to Recruit Young Women to Engineering," ASEE Annual Conference, 2005. 